\title{
Measuring the "Smartness" of the Electricity Grid
}

\author{
B. Dupont, Student Member, IEEE, L. Meeus, and R. Belmans, Fellow, IEEE
}

\begin{abstract}
Awareness among policy makers that electricity grids need to become smarter is growing. To allow policy makers to design policies for improving the smartness of grids, discussion is needed on what makes an electricity grid smart and how that this smartness can be measured. This paper provides a methodology to measure the smartness of the electricity grid. The defined framework consists of six characteristics which a smart grid should meet. Progress in the development of each characteristic is assessed by several key performance indicators. This allows to track the status of smart grid development.
\end{abstract}

Index Terms-Key Performance Indicators, Smart Grids, Smartness.

\section{INTRODUCTION}

$\mathrm{R}$ ECENTLY, worldwide energy policy is focusing more and more on a low carbon economy. For Europe, this is demonstrated by three ambitious 2020 targets [1], [2]:

--cutting greenhouse gas emissions by $20 \%$ compared with the 1990 level;

--reducing energy consumption by $20 \%$ (saving $13 \%$ when compared to 2006 levels);

--reaching a $20 \%$ share of energy from renewable energy sources.

These targets are a first step towards a $\mathrm{CO}_{2}$ neutral society in 2050. To accomplish these challenging goals, smart grids are recognised as a key issue. This is confirmed by the numerous working groups, projects and organisations that were initiated to facilitate the evolution of the Electricity Grid. For example, on a European level the Strategic Energy Technology plan (SET-plan) considers smart grids as one of the technological priorities [3]. This plan was followed by the European Industrial Initiative (EII) on Electricity Networks, entitled the "European Electricity Grid Initiative" (EEGI) which intends to make the European regulated grid players ready to host the energy mix foreseen by the EU Member States in 2020 and beyond [4]. The budget for the Research, Development \& Demonstration (RD\&D) of this program, is approximately $€ 2$ billion. This is supplemented by other industrial initiatives on renewable energy resources which also

R. Belmans, B. Dupont, and L. Meeus are with the Department of Electrical Engineering (ESAT), Div. ELECTA at the Katholieke Universiteit Leuven, Kasteelpark Arenberg 10, B-3001 Heverlee, Belgium (e-mail: ronnie.belmans@esat.kuleuven.be; benjamin.dupont@esat.kuleuven.be; leonardo.meeus@esat.kuleuven.be).

L. Meeus is also with the Florence School of Regulation, Villa Malafrasca, Via Boccaccio, 151I-50133 Firenze, Italy (e-mail: leonardo.meeus@eui.eu) contribute to the expansion of a smart grid. This states the interest, the necessity and the engagement in the development of an intelligent grid.

The evolution that the European electricity grid is about to face, should be guided by adequate regulation. Policy makers need to give the right incentives to encourage smart grid investments and need to make sure that projects improve all aspects of a smart grid. Therefore, an idea of what constitutes a smart grid and how this smartness can be measured is essential.

The U.S. Department of Energy applies the following characteristics to assess the status of American smart grid deployment [5]:

--enable informed participation by customers;

--accommodate all generation and storage options;

--sell more than kWhs;

--provide power quality for the 21 st Century;

--optimise assets and operate efficiently;

--operate resiliently to disturbances, attacks and natural disasters.

Though the defined characteristics show some overlap, they have a clear target that has to be met by the grid of tomorrow.

In Europe the debate on how to assess the deployment of smart grids is ongoing. This paper therefore builds further on the US framework to construct a tool to assess the level of development towards a European smart grid. This is just a starting point in the development of a methodology, where debate will play a crucial role. The defined methodology has not the intention to cover the entire scope of a smart grid. Refinement is needed in order to realise a proper framework on which can be built in the future.

In the following section the use of Key Performance Indicators (KPIs) is introduced. Section 3 gives a more indepth description of the six defined characteristics of an intelligent grid. Hereby, different KPIs are assigned to each of them in order to evaluate the smartness of the electricity grid. Finally, general conclusions are derived and recommendations for further research are made.

\section{KEY PERFORMANCE INDICATORS}

By formulating a set of Key Performance Indicators (KPIs) and applying those to the electricity network, the progress of smart grid development can be measured. Starting from the six characteristics of an intelligent grid defined above, KPIs are constructed. Several KPIs show some overlap with the metrics defined in the American smart grid system report [5], while others are created to face the European context. In order to get 
a thorough understanding of the status of smart grid development, the indicators are bound to the SMART-criteria, meaning they have to be Specific, Measurable, Attainable, Relevant and Time-bound [6].

These KPIs can serve multiple purposes. First of all, the list of KPIs can become a tool for regulators to assess the progress towards a smart grid both on a national and European level. This can allow policy makers to elaborate proper incentives to stimulate smart grid development. Moreover, the smartness of the national or European grid can be evaluated and compared with other countries or continents. Finally, the KPIs can be applied to evaluate project results on smart grids. A clearly defined framework can concretise where exactly the project contributed to a smart electricity grid.

\section{SMART GRID CHARACTERISTICS}

In order to evaluate the smartness of the electricity grid, KPIs are defined starting from the six defined characteristics of an intelligent grid. Table 1 gives an overview of the different KPIs specified to assess smart grid development. Each characteristic consists out of several categories to which different KPIs are assigned. In what follows a more in-depth description of the various characteristics, categories and KPIs is given.

\section{A. Enable Informed Participation by Customers}

In a smart electricity system, customers become an integral part of the electric power system. An intelligent grid allows the customers to take new choices resulting from new technologies, new information about electricity consumption, and new ways of electricity pricing. Five categories are defined to measure the progress of the electricity grid on this characteristic.

\section{Advanced Meters}

Advanced metering is a key technology to enable the informed participation of a customer. By installing advanced metering infrastructure, bi-directional communication ensures that energy consumption data, grid conditions, and real-time price information can be exchanged between the different parties. To measure progress in this area, two KPIs are defined in Table 1. These KPIs describe the penetration level of and the load that is served with advanced meter infrastructure. This allows to track the current implementation and evolution of those meters.

\section{Dynamic Pricing Signals}

Dynamic pricing signals give customers the opportunity to participate in the electric power systems. Real-Time-Pricing (RTP) tariffs are transmitted to the customers (residential, industrial, commercial), who can make informed decisions resulting in greater demand response. Table 1 states two KPIs that describe the penetration level of dynamic pricing signals from two points of view: the customers and the actual loads served by dynamic pricing structures.

\section{Smart Appliances}

Smart appliances can respond to the dynamic needs of a smart grid. They use software to communicate with the grid, which facilitates the reduction of load fluctuations, the decrease of peak loads, and eventually reduces the energy costs. Two KPIs are defined which identify the penetration level of smart appliances and the actual effectiveness of those appliances.

\section{Demand Side Management}

Because Demand Side Management (DSM) influences energy consumption, it forms an indicator for the level of active involvement of the customer in the energy system. In response to changes in the electricity price, end-consumers adapt their usual energy consumption pattern. This can result in load shifting and reduced costs through the smoothing of peak power consumption. An electricity grid is smart when it accommodates this behaviour. Three KPIs are suggested for measuring the smartness. These quantify the integration of DSM into the electricity market. This is expressed by the number of customers contributing in DSM, the load that can be re-allocated, and the time a certain load can be re-assigned. The KPIs should be split into four parts according to the residential, agricultural, commercial and industrial sector.

\section{Prosumer}

Distributed generation stored in the premises or buildings of the end-consumers, is penetrating the electricity market. In an intelligent grid an end-consumer not only buys electricity from the grid, but he can also deliver electricity to the grid becoming a "pro-sumer" in the electricity system. Bidirectional power flows are integrated in the electricity system, without jeopardising the grid stability. The three defined KPIs in Table 1 identify the evolution of consumers towards prosumers. Progress in this area is divided according to three areas: power, energy, and time. Again a distinction should be made based on the sector (residential, agricultural, commercial, and industrial).

\section{B. Accommodate all Generation and Storage options}

Distributed Generation (DG) is defined as an electrical generation unit connected to the electrical distribution system, at or close to the point of consumption [7]. Storage is another technology that comprises as well direct as indirect storage. It helps to bring flexibility into the electricity system. Heading for a $\mathrm{CO}_{2}$ neutral society against 2050, both DG \& storage will play a key role in accomplishing this target. Therefore a smart grid has to support the growing array of these technologies all along the value chain. It should allow the integration of decentralised and often intermittent energy sources in a plug-and-play environment.

\section{Distributed Generation and Storage}

DG and storage help realising the targets towards 2020 and beyond. Because of the intermittent nature of distributed generation, a mass implementation of these resources should be accompanied with storage and flexible loads to solve the problem of variability. The defined KPIs measure the penetration level of DG and storage in the electricity system. Due to the future impact on the electricity grid, Plug-in Hybrid Electric Vehicles (PHEVs) are not considered here and are allocated to a separate category. 
TABLE I

Characteristics, Categories, and Key Performance Indicators of a Smart Electricity Grid

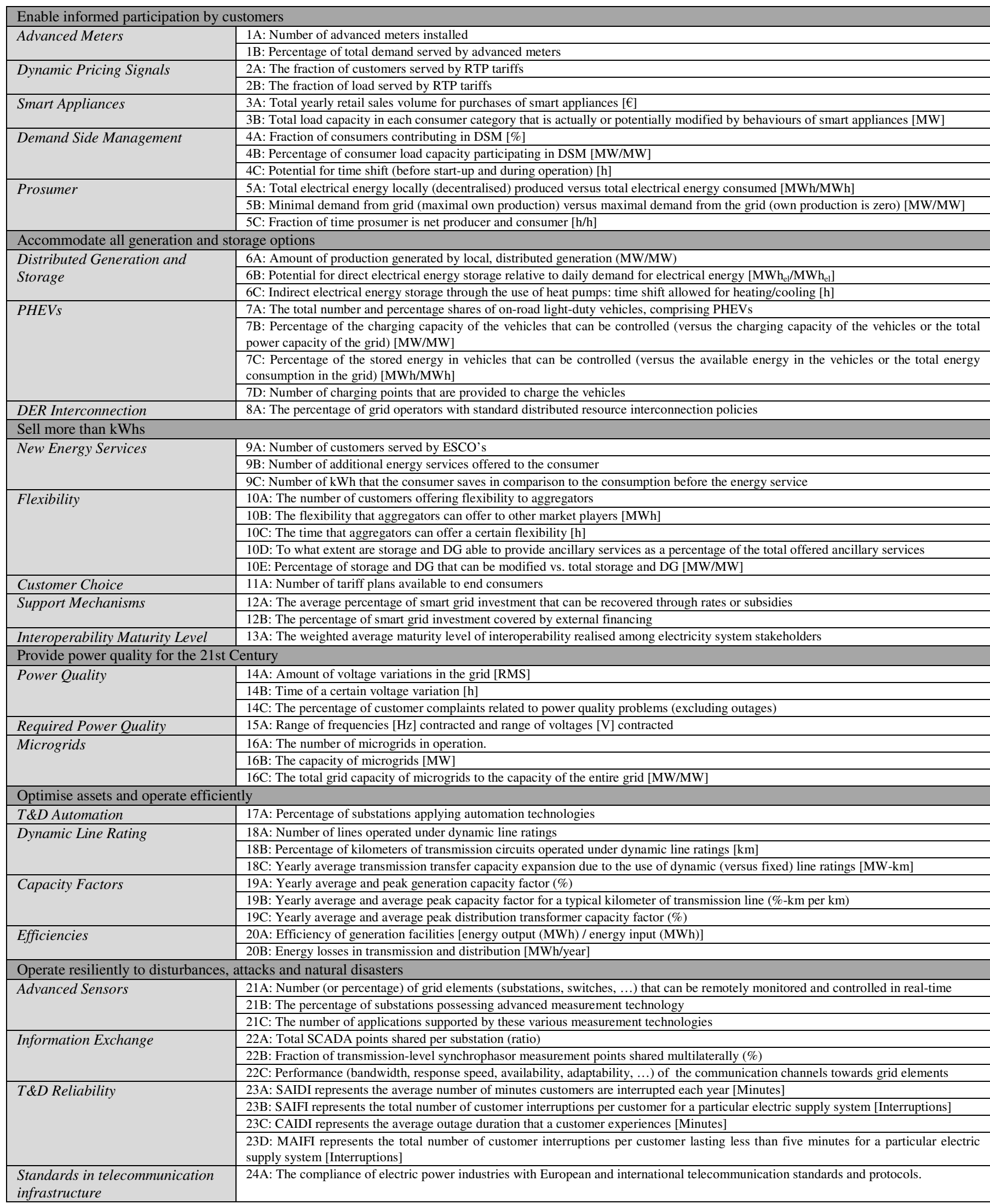




\section{PHEVs}

PHEVs are hybrid electric vehicles with batteries that can be recharged when plugged into an external electric power source. This allows customers to recharge their vehicles during off-peak hours and to sell energy to the grid operators during peak hours when prices are high. This helps reducing the peak load and thus also the cost of the power provided. Such behaviour should be enabled by the smart grid. The KPIs defined in this area evaluate the penetration of PHEVs and the extend in which the charging of those can be controlled.

\section{DER Interconnection}

Distributed Energy Resources (DER) consist of DG, the storage of electrical and thermal energy and/or flexible loads. These resources are rapidly integrating into the electricity system, therefore standard distributed resource interconnection policies should be designed. This way, easier and more consistent integration of DER is accomplished and the progress towards an intelligent grid is facilitated. European legislation, setting up these standards, is necessary to accommodate all generation and storage options. Table 1 shows one KPI that measures the extent to which standard interconnection policies are used in order to facilitate integration of DER and use them in an effective way.

\section{Sell more than $\mathrm{kWhs}$}

In a smart grid, more is sold than only kWhs. New products, services and markets rise in an energy system that gained a totally new perspective. End-users can purchase new technologies and services. They can offer flexibility to the grid operators by delivering power to the grid or by steering their loads. New market players like aggregators and Virtual Power Plants who optimise supply and demand, arise. The following categories and KPIs are defined in order to measure the progress in this area.

\section{New Energy Services}

In a smart grid, new services 'beyond the meter' (energy efficiency assessment, optimising energy bills, ...) are offered to customers. In literature, these services are typically performed by an Energy Service Company (ESCO) [7]. This is a natural or legal person that delivers energy services and/or other energy efficiency improvement measures in the user's facility or premises. By integrating the new services in the smart grid, the resulting added value can be captured. The defined KPIs in Table 1 assess the penetration level of new services in the energy market.

\section{Flexibility}

In an intelligent grid, new markets arise on which flexibility becomes a product that can be traded. New market players like aggregators will act as an intermediary between several electricity generators and other players in the electricity system by gathering flexibilities and contributions of consumers to build active demand services [7]. Five KPIs determine the extent to which flexibility is integrated in the electricity markets.

\section{Customer Choice}

In a smart grid context, customers can choose between different types of supply (green energy, lowest cost,...). Each type of supply corresponds with a tariff plan offered to the end consumer. The KPI in this area gives an indication of the degree of customer choice that a smart electricity market makes possible.

\section{Support Mechanisms}

A smart grid holds great potential for enabling new products, services and markets. Because this incorporates investments and risks, public and private interests should support the evolution towards a smart grid. A regulatory framework should stimulate smart grid behaviour and appropriate funding should be found for encouraging the proper integration of the new products and markets. Table 1 defines two KPIs that assess the extent to which smart grid investments are supported by public or private funding. Public funding can be installed by developing an adequate regulatory framework. In this case, investments in an intelligent grid can be recovered by raising the tariffs or by receiving subsidies. Private support can be measured by the available external financing for smart grid investments.

\section{Interoperability Maturity Level}

Open architectures and standards are a prerequisite to the success of new market creation in the electricity system. When implementing new products and services, alignment is needed on a technical, informational, and business level to ensure the interoperability among electricity system stakeholders. Measures of openness or standard adoption are difficult to obtain, therefore a European smart grid Interoperability Maturity Model (IMM) should be developed. This approach is based on the concepts derived from the software capability maturity model [8]. The concept is integrated in the KPI for measuring the progress of interoperability. Although this is an adequate indicator in this area, the use of this KPI depends on the development of a smart grid IMM.

\section{Provide Flexible Power Quality}

By connecting renewable, distributed energy sources to the electricity grid, the power quality may be affected [9]. Those resources have an impact on the voltage level, the frequency, and other parameters that determine the quality of electricity supply. Smart grids ensure that the expected power quality is delivered to its end-users. Therefore, advanced control methods, which monitor the essential components of the grid, should permit a proper and precise reaction to power quality events. Because not all end-users need the same power quality, an intelligent grid allows for a power quality level customised to each end-user. To capture the progress of development towards a sufficient, and flexible power quality level, the following categories are identified:

\section{Power Quality}

The integration of intermittent DG poses a great stress on the electricity grid. Even though this is accompanied with a lot of problems, the smart electricity grid should always provide the expected power quality to its customers. Therefore, the 
two KPIs stated in Table 1 should be kept in bound. These quantify the power quality of the electricity grid.

\section{Required Power Quality}

Not all customers (industrial, commercial, residential) need the same power quality. For example, power quality affects residential and industrial customers on a different level. A smart grid can provide different power qualities coupled with several pricing levels to the different end-consumers. One KPI is defined to describes the variation of delivered power quality to customers. This is determined by two parameters for power quality, namely the frequency and the voltage level. Each power quality level is accompanied by a pricing level. The more a grid operator can offer different pricing levels, the smarter the operation of the electricity grid.

\section{Microgrids}

A microgrid consists out of an integrated distribution system with interconnected loads and DER which operates connected to the main power grid [5]. It has the ability to be islanded from the main power grid with coordinated control, providing sources of reliable power quality. Due to the growing attention in microgrids in some European countries, this category is represented in this paper. Table 1 states KPIs that measure the penetration level of microgrids in an intelligent grid based on three areas: the number, the absolute capacity, and the relative capacity of microgrids.

\section{E. Optimise Assets and Operate Efficiently}

On average, the European electricity grid is around 40 years old [10]. While these ageing assets obviously need to be reinforced or replaced with new investments, the options of further developing the grid need to be well chosen. When replacing existing assets, one should take into account the flexibility towards further developments. If the existing assets are maintained advanced materials, equipment, and information and communication technologies can be used to optimise the existing assets. The following list of categories is identified to cover the progress in this area.

\section{$T \& D$ Automation}

In a smart grid, automation occurs at all levels of the electricity grid from transmission to end-user. This way, components are monitored, coordinated and operated from remote locations. State-of-the-art power technologies are used to operate the system closer to its capacity and stability constraints, eventually leading to a more efficient operation of the electricity grid. Table 1 defines one KPI that measures the penetration of T\&D automation in the electricity system. Before analysing this KPI, an adequate definition of automation should be developed. Different technologies should be captured by this definition: Supervisory Control \& Data Acquisition (SCADA) technologies, remote sensors and monitors, switches, and digital relays are some examples though a rise of new technologies can be expected. When these new technologies become available, these should be included in the description of T\&D automation.

\section{Dynamic Line Rating}

Dynamic line ratings form a tool for enhancing the capacity of the electrical grid. It uses actual weather conditions, surface temperature monitoring, tension monitoring, and loading conditions to rate the impact on the transmission grid. This increases the utilisation of assets by operating the grid closer to its capacity. The KPIs from Table 1 measure to which extent dynamic line rating is applied in the transmission grids.

\section{Capacity Factors}

The level of optimisation of electricity infrastructure can be evaluated by making use of capacity factors. These factors describe the ratio of the energy that is actually produced or delivered during an interval, compared to the amount of energy that could have been produced or delivered. This illustrates the state of the electricity grid and can be used to evaluate the evolution towards a smart grid. Table 1 indentifies KPIs that evaluate the capacity on three levels of the electricity system: generation, transmission, and distribution. For each of them the capacity factor is defined from the average and the peak capacity. A smart grid evolution is expected to bring these values closer to each other.

\section{Efficiencies}

Smart grids optimise operating efficiency and asset utilisation by applying advanced information and communication technologies. An intelligent grid should lead to a more efficient operation of generation facilities and to less energy losses in the transmission and distribution system. Two KPIs stated in Table 1 measure the efficiencies of the electricity system from generation to distribution.

\section{F. Operate resiliently to disturbances, attacks and natural disasters}

A smart grid should operate in a reliable way, whether system disturbances like voltage sags and frequency oscillation occur, or whether the electricity grid is exposed to physical and cyber attacks or natural disaster. In both cases an intelligent grid prevents and heals these problems by accurately monitoring, controlling and automating the electricity grid. New devices, equipment, designs, monitoring systems, and communication standards are used to operate the grid in a self-healing and resilient way. In order to meet these requirements, the following categories are defined.

\section{Advanced Sensors}

A smart grid uses tools for improved observability on network interactions to construct realistic pictures of the state of the electric system increasing situational awareness. Therefore Wide Area Measurement Systems (WAMS) are incorporated. These systems apply advanced-technology infrastructure that is used for an increased observability of the electricity grid. This leads to an increased situational awareness with a level of exploitation closer to stability limits and an improved control of the network. Problems can be tracked and solved in a rapid and efficient way, making the grid less susceptible to disturbances. In order to quantify progress in this area, Table 1 states three KPIs that measure the penetration of advanced sensors in the electricity system.

\section{Information Exchange}

The integration of advanced sensors throughout the 
electricity grid makes the development of an information architecture indispensible. System status information should be exchanged between all relevant market players. Information exchange between national TSOs, day-to-day data exchanges between the TSO and DSO, and an interconnected information process between the customers and the grid should be set in place in order to counter any disturbances. Three KPIs are defined that assess the integration of information exchange mechanisms in the electricity system. This is divided according to the quantity and the quality of data sharing.

\section{$T \& D$ Reliability}

As well as in a traditional electricity grid, reliability is one of the key aspects of a smart electricity grid. In all circumstances, the reliability has to be assured. An indication of reliability can be retrieved from the widely applied metrics SAIDI (System Average Interruption Duration Index), SAIFI (System Average Interruption Frequency Index), CAIDI (Customer Average Interruption Duration Index) and MAIFI (Momentary Average Interruption Frequency Index). These KPIs give an indication of the reliability of the electricity system.

\section{Standards in telecommunication infrastructures}

Because of the high interconnected nature of the communication standards, European standards for monitoring, controlling and automation become necessary. European standards in line with the on-going National Institute of Standards and Technology (NIST) [11] approach in the US should be specified to avoid all kind of malfunctions in the electricity grid. Table 1 defines one KPI that determines the penetration level of overall telecommunication standards and protocols in the electricity system.

\section{CONCLUSIONS AND RECOMMENDATIONS FOR FURTHER RESEARCH}

The defined methodology consists out of six characteristics, each accompanied by several KPIs which measure the smartness of the grid. In order to make the KPIs applicable for evaluation, they were constructed based on the SMARTcriteria. Heading towards a smart electricity grid, policy makers should encourage progress in all six characteristics. Failure to meet one or more of the characteristics, limits the total benefits of a transition towards an intelligent grid.

After the methodology is developed, research is needed to attain the necessary data \& information. Workshops, interviews, surveys, studies, and research of existing literature are essential for the succeeding of this exercise. This is a challenging opportunity, because the whole value chain of the electricity market should be involved to catch the adequate information. Some data on KPIs are easy to track, whereas the finding of other data experiences some counteractions, especially due to the relative newness of the smart grid.

\section{ACKNOWLEDGEMENT}

The authors gratefully acknowledge the contributions of all the colleagues of the ELECTA division and TME division at the Katholieke Universiteit Leuven for assisting in the development of the KPIs.

\section{REFERENCES}

[1] European Council, "Climate-Energy Legislative Package", 2009. Available: http://www.consilium.europa.eu/uedocs/cms_data/docs/ pressdata/en/misc/107136.pdf

[2] European Parliament, " resolution on the Action Plan for Energy Efficiency", T6-0033/2008, 2008. Available: http://www.europarl.europa.eu/oeil/file.jsp?id=5484562

[3] European Commission, "R\&D investment in the priority technologies of the SET-plan", SEC(2009)1296.

[4] The European Electricity Grid Initiative (EEGI), "A joint TSO-DSO contribution to the European Industrial Initiative (EII) on Electricity Networks", 2009.

[5] U.S. Department of Energy, "Smart Grid System Report", 2009. Available: http://www.oe.energy.gov/DocumentsandMedia/SGSRMain _090707_ lowres.pdf, and http://www.oe.energy.gov/Documentsand Media/SGSR_Annex_A-B_090707_lowres.pdf

[6] M.A. Mahbod, A. Shahin, "Prioritization of Key Performance Indicators", International Journal of Productivity and Performance Management, 2006.

[7] G. Bourgain, J. Deuse, S. Galant, A. Vafeas, "Integrating Distributed Energy Resources into today's electrical system", 2009, EU-DEEP.

[8] Software Engineering Institute, "The Capability Maturity Model for Software", 2008, Carnegie Mellon University, Pittsburgh, Pennsylvania. Available: http://sei.cmu.edu/cmm/

[9] J. Driesen, R. Belmans, "Distributed Generation: Challenges and Possible Solutions", 2006, IEEE Power Engineering Society General Meeting, Institute of Electrical and Electronics Engineers, Piscataway, New Jersey.

[10] A. J. Gaul, J. Nilges, E. Nockmann, and H. Spitzer, "Asset simulation an approach to predict the long term monetary consequences of maintenance and renewal strategies for electrical grids", $19^{\text {th }}$ International Conference on Electricity Distribution (CIRED), Vienna, 21-24 May 2005.

[11] National Institute for Standards and Technology (NIST), http://www.nist.gov/index.html 